\title{
Investigation of tectonic processes in the lunar South Polar Region using Mini-SAR and other data
}

\author{
Saumitra Mukherjee* and Priyadarshini Singh \\ Department of Environmental Sciences, Remote Sensing and Geology, School of Environmental Sciences, Jawaharlal Nehru University, Delhi, India \\ ${ }^{*}$ Correspondence: saumitra@mail.jnu.ac.in
}

Edited and reviewed by:

Yosuke Aoki, University of Tokyo, Japan

Keywords: Chandrayaan, MiniSAR, tectonics, lunar science, double bound scattering, ejecta blanket

\section{A commentary on}

Terrestrial and lunar faults compared by Shwarz, E. H. L. (1928). J. Geol. 36, 97-112.

Studies focusing on the geological processes on the moon have found various tectonic features suggesting similar geological activity occurring on the Earth (Shwarz, 1928). Also, it can be inferred that meteoritic impact, cosmic and solar wind flux variability coupled with the interior changes of the Moon may have manifested in the form of tectonic activity on the moon. Lobate scarps which are generated from thrust faulting on the moon and are indicative of recent tectonic activity have also been identified in the sub-polar and equatorial regions (Watters et al., 2010). Alternatively, "grabens" which are indicative of extensional tectonics have also been identified at various locations in the South Polar Region (Kramer et al., 2012).

Previous studies investigating tectonic activity have used optical data primarily to study lunar tectonics. But areas such as partially and completely shadowed crater interiors present in the polar regions can also contain unique features indicative of tectonic activity. The study therefore focuses on the identification of features indicating the presence of faults/lineaments/ fractures on the lunar topography using mini-SAR data from CHANDRAYAAN-1 mission as well as optical data from Wide Angle Camera (WAC) and Narrow Angle Camera (NAC) from LROC mission.

Mini-SAR imaging radar onboard CHANDRAYAAN-1 mission was the first mono-static lunar orbiting synthetic aperture radar (Spudis et al., 2009). MiniSAR data is primarily used to identify signatures suggesting the possibility of the presence of water ice within the completely shadowed regions of the lunar poles (Fa and Cai, 2013). Further, this data has been used to view various other geological features such as melt flows, crater ejecta blankets, secondary craters etc. (Saran et al., in press). Therefore, identification of distinct morphological features in shadowed as well as illuminated regions of lunar surfaces can be easily done using mini-SAR data (Spudis et al., 2009). The SAR technology can also penetrate the surface and therefore is an effective tool to look for hidden fault lines in the shadowed portions on the lunar regolith. Alternatively, other distinct surface and subsurface geological features have also been identified which can further help to study the process of impact cratering as well as understand the formation of secondary features developed post impact.

Digital image processing of mini-SAR data using $\mathrm{m}-\chi$ decomposition technique was done to achieve single, double, and multiple/diffuse backscattering contributions to view tectonically derived morphological features in detail (Saran et al., 2012). Fault lines overlying possible subsurface faults depicting presence of past or present seismic activity can be seen well after using $\mathrm{m}-\chi$ decomposition technique. Other features such as rock/ debris avalanches within the inner crater walls were also identified lying perpendicular to the inferred fault lines on $\mathrm{m}-\chi$ decomposition images within the South Polar Region. Slumping activity on the shadowed inner crater walls forming terraced structures can also be seen using $\mathrm{m}-\chi$ decomposition images. These could have formed due to nearby impact shaking or seismic activity from underlying dislocation along fault planes making the material to slide down in single or multiple blocks.

Circular polarization ratio $(\mathrm{CPR})$ was another parameter calculated to infer surface roughness in the regions having the tectonically derived features. Circular polarization ratio gives the ratio of the same sense circular polarization backscatter power received as emitted over the opposite sense backscatter power received as emitted (Calla et al., 2013). The inferred rock/ debris avalanche associated with tectonic activity have high values of CPR ranging between $0.1-2.7$, which indicates the presence of highly rough surfaces. Such type of mass wasting activity can also be seen on terrestrial hilly terrains being formed after seismic shaking of unconsolidated material.

Microwave remote sensing therefore helps to reveal a number of geological features on varying terrains otherwise not visible on optical data. Mini-SAR data makes it easy to view several of such unique features over the lunar surface both in the illuminated and the shadowed regions. The identification of such features can help to further understand the past and present geological activity taking place resulting in the formation of such features. It can also explain the physics behind the process of impact catering and the subsequent formation of other secondary structures. Further the results obtained can be correlated and compared with similar features seen on terrestrial surfaces.

High CPR values derived from Stokes vectors and degree of polarization can primarily be attributed to the rough and rugged surfaces mainly found on the inner walls of impact craters and on the outer 
rim due to the proximal ejecta blanket. Other features like the rocky avalanches also show high CPR values and volume scattering obtained due to rough surfaces from rocky debris formed after the dislocation and subsequent disintegration of the material on sloping crater walls.

\section{ACKNOWLEDGMENTS}

Authors acknowledge Indian Space Research Organization for financial support.

\section{REFERENCES}

Calla, O. P. N., Mathur, S., and Jangid, M. (2013). "Water ice detected at secondary craters on peary floor using Mini-SAR and Mini-Rt," in Proceedings of the Large Meteorite Impacts and Planetary Evolution V, Abstract 3008 (Sudbury, ON).

Fa, W., and Cai, Y. (2013). "Analysis of CPR characteristics for anomalous craters and implications for lunar ice detection," in 44th Lunar and Planetary Science Conference, Abstract 1470 (Woodlands, TX).
Kramer, G. Y., Öhman, T., Nahm, A. L., and McGovern, P. J. (2012). Pre- and Post-Impact Influences On Schrödinger Basin's Structural Geology, LPSC XLIII, Abstract 1734. (Houston, TX).

Saran, S., Das, A., Mohan, S., and Chakraborty, M. (2012). Study of scattering characteristics of lunar equatorial region using Chandrayaan-1 Mini-SAR data. Planet. Space Sci. 71, 18-30. doi: 10.1016/j.pss.2012. 06.014

Saran, S., Das, A., Mohan S., and Chakraborty, M. (in press). Synergetic use of SAR and thermal infrared data to study the physical properties of the lunar surface. J. Adv. Space Res. doi: 10.1016/j.asr. 2013.10.029

Shwarz, E. H. L. (1928). Terrestrial and lunar faults compared. J. Geol. 36, 97-112.

Spudis, P., Nozette, S., Bussey, B., Raney, K., Winters, H., Lichtenberg, C. L., et al. (2009). Mini-SAR: an imaging radar experiment for Chandrayaan-1 mission to the Moon. Curr. Sci. 96, 533-539. doi: $10.1029 / 2009 \mathrm{gl042259}$

Watters, T. R., Robinson, M. S., Beyer, R. A., Banks, M. A., Bell III, J. F., Pritchard, M. E., et al. (2010). Evidence of recent thrust faulting on the moon revealed by the lunar reconnaissance orbiter camera. Science 329, 936-940. doi: 10.1126/ science. 1189590

Conflict of Interest Statement: The authors declare that the research was conducted in the absence of any commercial or financial relationships that could be construed as a potential conflict of interest.

Received: 30 January 2014; accepted: 17 April 2014; published online: 06 May 2014.

Citation: Mukherjee S and Singh P (2014) Investigation of tectonic processes in the lunar South Polar Region using Mini-SAR and other data. Front. Earth Sci. 2:6. doi: 10.3389/feart.2014.00006

This article was submitted to Structural Geology and Tectonics, a section of the journal Frontiers in Earth Science.

Copyright (c) 2014 Mukherjee and Singh. This is an open-access article distributed under the terms of the Creative Commons Attribution License (CC BY). The use, distribution or reproduction in other forums is permitted, provided the original author(s) or licensor are credited and that the original publication in this journal is cited, in accordance with accepted academic practice. No use, distribution or reproduction is permitted which does not comply with these terms. 